\title{
Durability of Recycled Aggregate Concrete
}

\author{
Naouaoui Khaoula*, Azzeddine Bouyahyaoui, Toufik Cherradi \\ Mohammadia School of Engineers, Mohamed V University Agdal, Rabat, 10000, Morocco
}

\author{
A R T I C L E I N F O \\ Article history: \\ Received: 06 November, 2020 \\ Accepted: 12 January, 2021 \\ Online: 05 February, 2021
}

Keywords:
Durability
Recycled aggregates
Concrete

Keywords:

Recycled aggregates

Concrete

\begin{tabular}{l} 
A B S T R A C T \\
Many countries all over the world are promoting the recycled aggregate concrete for its \\
advantage to solve the problem of shortage of natural resources in aggregates as well as \\
promoting the recycling of waste and the reuse of materials. Recycled aggregate concrete \\
replaces natural concrete with various rates of restitution of natural aggregates into \\
recycled aggregates. The choice of rate is essential in the quality of the finished concrete \\
and depends on the mechanical and durability characteristics. Tests in the civil engineering \\
laboratory of the Mohammadia School of Engineers - Rabat Morocco have shown that above \\
a rate of $30 \%$ the mechanical characteristics drop. The addition of adjuvants / side products \\
helps to increase this rate and a concrete with a 50\% restitution can be used instead of \\
natural concrete. Our study, the subject of this document, aims to study the durability of this \\
concrete for various percentages of restitution. The experimental tests focused on \\
determining the porosity of hardened concrete. The results were between 13 and $14 \%$ for all \\
of the restitution percentages. This study concluded that for ordinary constructions, this \\
concrete meets the criteria of the Perfertial Approach for durability. For projects with \\
special criteria, other more in-depth studies will have to be carried out. \\
\hline
\end{tabular}

\section{Introduction}

Durability of concrete is the ability of concrete to resist to various types of damage, maintaining its strength and appearance integrity for its service period of exposure to its surrounding environment. Compared with nature aggregate concrete (NAC), the durability of recycled aggregate concrete (RAC) is usually weaker than NAC due to the adhered- mortar on the recycled aggregates (RA). The durability tests include deformation (drying shrinkage), impermeability, chloride penetration resistance, carbonation resistance, frost resistance and alkali aggregate reaction.

The benchmarking of many studies has demonstrated that the impermeability of RAC decreases with an increase of the replacement ratio of RA. Due to the capillary channels in the concrete system, fine elements of the recycled aggregates affects the impermeability more that the coarse ones [1-6]. In another side, the increase of coarse recycled aggregates increases the water absorption of concrete by immersion and capillarity regardless of the quality of RA.

${ }^{*}$ Corresponding Author: NAOUAOUI Khaoula, Mohammadia School of

Engineers, Mohamed V university agdal Rabat, naouaoui.khaoula@gmail.com
For the chloride penetration resistance, the studies prove that it is lower in the RAC compared to NAC [7]. However, it was found that when RA was prepared with a low water /cement $(\mathrm{w} / \mathrm{c})$ ratio, it exhibits better performance than NAC in a chloride environment, probably due to the presence of higher C-S-H gels in RAC, which assists in chloride binding [8]. The carbonation depth increases, as many other durability properties, with the increase of RA replacement ratio. Many studies focused on the influence of different parameters on the carbonation resistance. They found that the increase of RA content, w/c ratio, and adhered mortar have a strong negative effect on it, the increase of exposure time or pozzolanic materials have negative effect when the presence of super-plasticizers, the pre-treatment of RA and the use of innovated mixing method affect positively the carbonation resistance.

Concerning the weak frost resistance, the RAC is not recommended in a harsh environment. However, the RAC, with a $\mathrm{w} / \mathrm{c}$ ratio below 0.5 and incorporating $5 \%$ air content, can still be used in unsaturated and moderate cold climates [9]. The reduction of the amount of mixing water and the water saturation of the samples or the incorporation of a proper amount of fly ash and an air-entraining agent can help to improve the frost resistance [9-12]. 
Many methods have been proposed to improve the durability of concrete based on recycled aggregates [13-16] such us removing the adhered mortar of RCA. The adhered mortar content in RCAs has an obvious impact on strength and durability of RAC. Due to the presence of the adhered mortar, RCAs have a higher permeability than the natural aggregates.

Another method proposed is the use of the Two-Stage Mixing Approach (TSMA). The technique used is to divide the mixing process into two parts and proportionally splits the required water into two, which are added at different times us shown in Figure 1 illustrating the difference between normal mixing approach and TSMA mixing procedures [17].

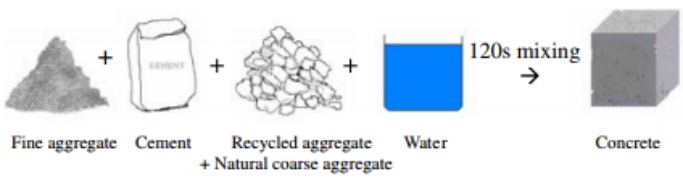

(i) NMA

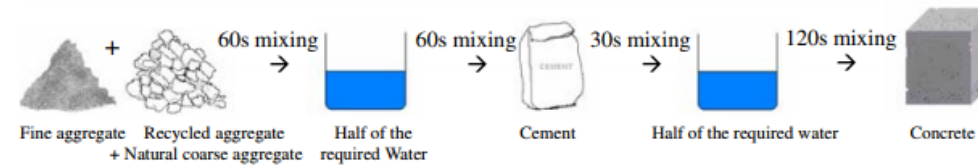

(ii) TSMA

Figure 1: Mixing Procedures of the (i) Normal Mixing Approach and (ii) TwoStage Mixing Approach

The Experimentation highlights that the deformation and permeability of RAC can be enhanced by adopting TSMA with up to $68.09 \%$ on shrinkage (with $100 \%$ RA substitution after 14 days of curing). The increase is up to $46.42 \%$ on creep (with $100 \%$ RA substitution after 14 days of curing), $35.41 \%$ on water permeability (with $100 \%$ RA substitution after 126 days of curing), $51.81 \%$ on air permeability (with $20 \%$ RA substitution after 56 days of curing) and $29.98 \%$ on chloride permeability (with $100 \%$ RA substitution after 126 days of curing).

The third improvement method proposed is to enhance the characteristics of RCA without removing adhered mortal by using physical and chemical methods. The main methods used are [18] the impregnation by a foreign chemical to block the open porosity of RCA or the Use of polyvinyl alcohol (PVA)-impregnated method to improve the resistance to chloride-ion penetration. We might also use materials as additives like pozzolanic materials (specially pulverized fly ash or ground granulated blast furnace slag) or water repellent to improve the cement matrix in RAC and enhance the durability by reducing the permeability of RAC. These techniques may have inconvenient like reducing the compressive strength of RAC [14, 15, 19, 20]. We can also adopt an accelerated carbonation technique to enhance the quality of RCA as well as the mechanical properties.

\section{Compressive strength of recycled aggregate concrete: Overview of the experimental study}

Recycled aggregate concrete is a large-scale concrete that has been used in several countries for years.

In Morocco, RCA is subject to several types of research in order to encourage its local use.
As part of the valuation of the RAC, a mechanical comparison was drawn up in order to highlight the technical possibility of replacing normal concrete with recycled aggregate concrete.

The study protocol is devised to three main parties: Study of the characteristics of recycled aggregates (water content, water absorption) in order to highlight the quality of the aggregates. The second step is the formulation of the RAC according to the DreuxGorisse method based on the desired characteristics in the concrete and on the particle size analysis of natural and recycled aggregates and finally the compressive strength experimental tests.

\subsection{Water content ( $W \%)$}

The water content is equal to the ratio of the mass of water contained in the sample to the mass; we can calculate it using the following relation:

$$
W=100 * \frac{M-M_{S}^{\prime}}{M_{S}}
$$

with

\section{W: Water content}

M: The mass of the sample

M's: The mass of the sample oven dried at $105^{\circ} \mathrm{C}$ to constant mass without prior washing.

$\mathrm{M}$ s: The mass of the sample washed on the $4 \mathrm{~mm}$ sieve and oven dried at $105^{\circ} \mathrm{C}$ to constant mass.

Table 1: Water content experimental results

\begin{tabular}{|l|c|c|c|c|c|}
\hline \multicolumn{3}{|c|}{ Recycled aggregates 5-12.5 } & \multicolumn{3}{c|}{ Recycled aggregates 12.5-31.5 } \\
\hline M (g) & M's (g) & M s (g) & M (g) & M's (g) & M s (g) \\
\hline 2000 & 197.6 & 1975.32 & 2000 & 1915 & 1963.8 \\
\hline \multicolumn{3}{|c|}{ W } & \multicolumn{3}{c|}{ W } \\
\hline \multicolumn{3}{|c|}{$1.49 \%$} & \multicolumn{3}{c|}{$4.32 \%$} \\
\hline
\end{tabular}

The comparison between two recycled aggregates of two different classes: Recycled aggregates with particle size 5-12.5 and recycled aggregates with particle size 12.5-31.5 showed that the water content is greater for large aggregates. This is justified by the presence of several pores, which disappear during the fine crushing of the aggregates.

\subsection{Water absorption rate (AB \%)}

Water absorption by definition is the quotient of the mass of a sample immersed in water for 24 hours at $20^{\circ} \mathrm{C}$ and atmospheric pressure, by its dry mass. It is determined according to the relation below:

$$
A_{b}=100 * \frac{M_{a}-M_{s}}{M_{s}}
$$

where:

\section{Ab: Water Absorption}

Ms: The mass of the sample washed on the $4 \mathrm{~mm}$ sieve and oven dried at $105^{\circ} \mathrm{C}$ to constant mass. 
N. Khaoula et al. / Advances in Science, Technology and Engineering Systems Journal Vol. 6, No. 1, $735-741$ (2021)

Ma: The mass of the sample immersed in water for 24 hours at $20^{\circ} \mathrm{C}$ at atmospheric pressure and carefully blotted with an absorbent cloth.

Table 2: Water absorption rate experimental results

\begin{tabular}{|c|c|c|c|}
\hline \multicolumn{2}{|c|}{ Recycled aggregates 5-12.5 } & Recycled aggregates 12.5-31.5 \\
\hline $\mathrm{Ms}(\mathrm{g})$ & $\mathrm{Ma}(\mathrm{g})$ & $\mathrm{Ms}(\mathrm{g})$ & $\mathrm{Ma}(\mathrm{g})$ \\
\hline 1975.32 & 2194.8 & 1963.8 & 2148.4 \\
\hline \multicolumn{2}{|c|}{$\mathrm{Ab}$} & \multicolumn{2}{|c|}{$\mathrm{Ab}$} \\
\hline \multicolumn{2}{|c|}{$11.11 \%$} & $9.4 \%$ \\
\hline
\end{tabular}

The comparison between the two recycled aggregates of two different classes has shown that the water absorption rate is higher for small aggregates. This is justified by the superiority of the contact surface.

\subsection{Particle size analysis}

The particle size analysis is the main experimental step to formulate the concrete and to compare the recycled aggregates with the natural ones, the results of the particle size analysis are as follows, and the graph represents the rate of cumulative sieves relative to each opening of the sieve. The sieves used are standards ranging from 0.08 to $31.5 \mathrm{~mm}$.

The four aggregates tested are: GR 5-12,5 relative to recycled aggregate with particle seize between 5 and $12,5 \mathrm{~mm}$, GR 12.5131.5 relative to recycled aggregate with particle seize between 12.5 and $31,5 \mathrm{~mm}$, GN 5-12,5 relative to natural aggregate with particle seize between 5 and 12,5 mm GN 12.5-31.5relative to natural aggregate with particle seize between 12.5 and $31.5 \mathrm{~mm}$.

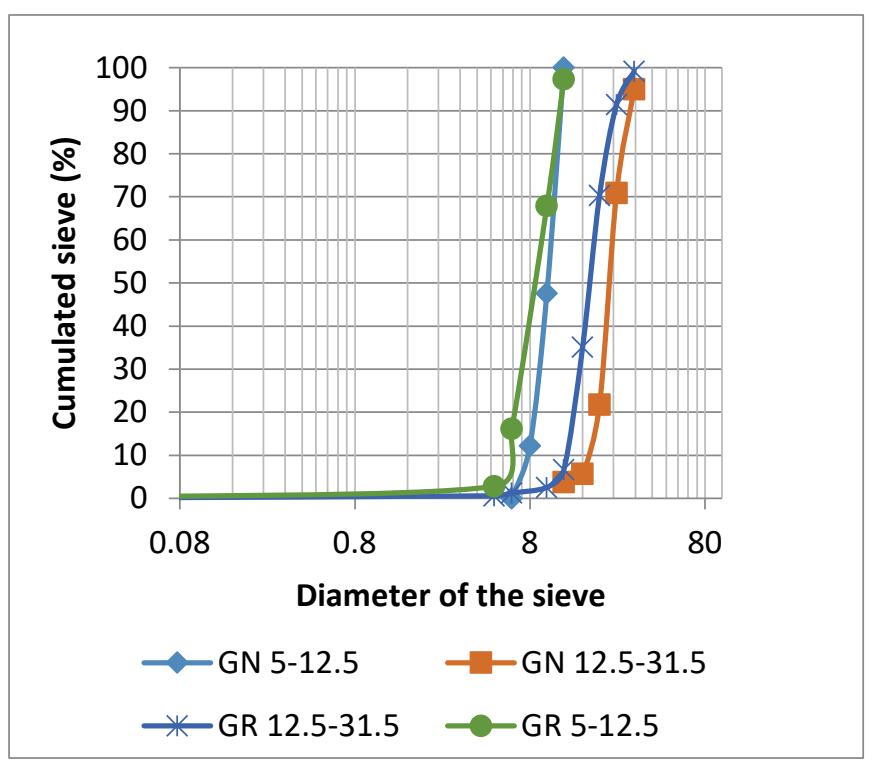

Figure 2: Granular curve for natural and recycled aggregates used in experimental study.

The interpretation of the granular curves shows that:

- The backbone of GR5-12.5 and GN5-12.5 is almost identical, at the opening $10 \mathrm{~mm}$ for example the percentage of the cumulative sieve of GN5-12.5 is almost 50\% and of GR5-12.5 is $60 \%$.
- The distribution of the various sizes of GR12.5-31.5 and GN12.5-31.5 aggregates is different.

Table 3: Differences between GR2 and GN2 in term of size analysis.

\begin{tabular}{|c|c|c|}
\hline \multirow{2}{*}{$\begin{array}{c}\text { Diameter of the } \\
\text { standard sieve }\end{array}$} & \multicolumn{2}{|c|}{ Cumulated sieve \% } \\
\cline { 2 - 3 } & GN12.5-31.5 & GR12.5-31.5 \\
\hline 5 & 0,00 & 0,60 \\
\hline 12,5 & 3,77 & 6,64 \\
\hline 16 & 5,76 & 35,10 \\
\hline 20 & 21,81 & 70,35 \\
\hline 25 & 70,87 & 91,41 \\
\hline 31,5 & 100,00 & 99,13 \\
\hline
\end{tabular}

This distribution is favorable for GR12.5-31.5, it allows having less voids and pores in our concrete, which compensate for the defects of the recycled aggregates.

Based on the particle size analysis, the formulation chosen using Dreux-Gorisse method is:

Table 4: Concrete formulation

\begin{tabular}{|c|c|c|}
\hline Component & Volume $\left(\mathrm{m}^{3}\right)$ & Mass $(\mathrm{kg})$ \\
\hline Water & 0.19 & 190 \\
\hline Cement & 0.29 & 350 \\
\hline Sand & 0,17 & 472,85 \\
\hline Gravel 5-12.5 & 0,15 & 376,14 \\
\hline Gravel 12.5-31.5 & 0,2 & 537,3 \\
\hline
\end{tabular}

\subsection{Compression test of pre-established concrete specimens}

Compressive strength is the main characteristic of concrete in the medium term; identification tests and comparisons were carried out in the civil engineering laboratory of the Mohammadia School of Engineers and were based on changes in the replacement rate. Natural aggregates with recycled aggregates by opting for 0 , $20,30,50,75$ and $100 \%$ recycled aggregates.

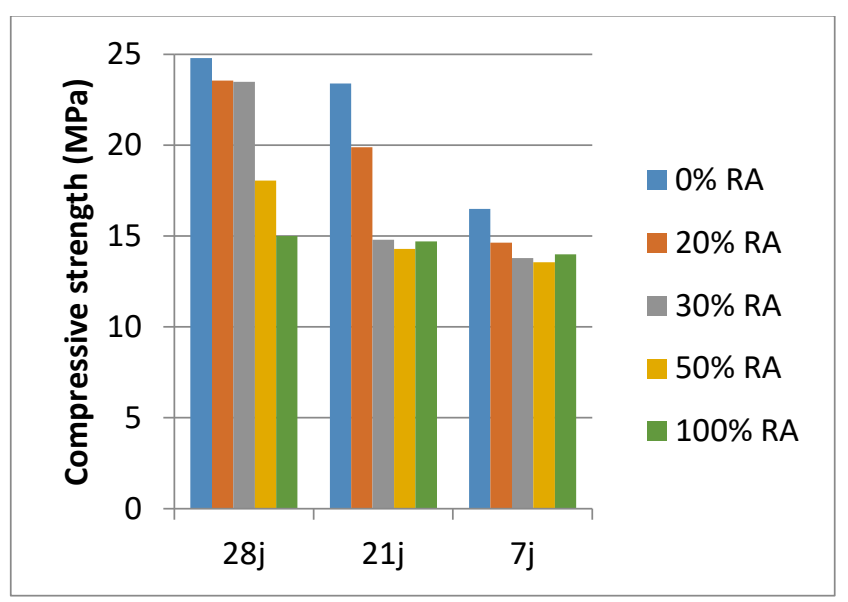

Figure 3: Compression test experimental results 
The results interpretation is focused on the results at 28 days, we notice that with the increase in the replacement rate the compression decreases whether it is short term. We also notice that beyond $30 \%$ replacement the decrease in the value of compression exceeds $10 \%$.

The second stage of the tests consists of improving the quality of the concrete in order to broaden its field of use and increase the replacement rate.

The proposed solution is to add various types of admixture in order to see the effect on the compressive strength of the type of admixture and the percentage of restitution used.

Our protocol is fixed on the use of three adjuvants: Plasticizer: BV 40, Super-plasticizer: Tempo 10M and the new generation super-plasticizer: SFR. These products are from the SIKA brand produced by SIKA MAROC installed in BOUSKOURA Casablanca.

The choice of these three types is justified by the fact that we wanted to determine the effect of the type of admixture on our concrete.

Table 5: Compression test experimental results with and without adjuvant

\begin{tabular}{|c|c|c|}
\hline $\begin{array}{c}\text { \% of } \\
\text { RA }\end{array}$ & $\begin{array}{c}\text { Compressive strength at } \\
28 \text { days without } \\
\text { adjuvant }-\mathrm{MPa}\end{array}$ & $\begin{array}{c}\text { Compressive strength at 28 } \\
\text { days with adjuvant (Tempo } \\
10 \mathrm{M}-1 \% \text { ) }-\mathrm{MPa}\end{array}$ \\
\hline 25 & 23.52 & 24,3 \\
\hline 50 & 18,05 & 21,45 \\
\hline 75 & 17,7 & 20,47 \\
\hline 100 & 15 & 19,65 \\
\hline
\end{tabular}

Results show that adding admixture improves compressive strength.

A comparison between various types of adjuvant proves that the plasticizer and super-plasticizer give better results than the new generation super-plasticizer as shown in table 5.

Table 6: Compression test experimental results with different adjuvants

\begin{tabular}{|c|c|c|c|c|}
\hline $\begin{array}{c}\% \\
\text { RA of }\end{array}$ & $\begin{array}{l}\text { Type of } \\
\text { adjuvant }\end{array}$ & $\begin{array}{c}\% \text { of } \\
\text { adjuvant }\end{array}$ & $\begin{array}{l}\text { Compressive } \\
\text { strength at 7 } \\
\text { days - MPa }\end{array}$ & $\begin{array}{l}\text { Compressive } \\
\text { strength at 28 } \\
\text { days-MPa }\end{array}$ \\
\hline \multirow{2}{*}{50} & BV40 & & 19,87 & 22,63 \\
\cline { 2 - 3 } & SFR & \multirow{2}{*}{$1 \%$} & 11,50 & 16,65 \\
\cline { 5 - 6 } & $\begin{array}{c}\text { Tempo } \\
10 \mathrm{M}\end{array}$ & & 17,47 & 21,45 \\
\hline
\end{tabular}

The interpretation of these results is that adding a fairly complicated and developed formulation full of additive does not interact well with our attached cement.

The choice of the percentage of replacement of the binder by adjuvant is essential in the expected results. For each adjuvant, a recommended range of use is specified on the technical sheet for each product.

Experimental tests alone are able to choose the optimum value.
In our case, $1 \%$ constitutes our value chosen as being equivalent to the maximum of the test results (table 7)

Table 7: Compression test experimental results with different percentage of the adjuvant

\begin{tabular}{|c|c|c|c|c|}
\hline $\begin{array}{c}\% \text { of } \\
\text { RA }\end{array}$ & $\begin{array}{c}\% \text { of } \\
\text { adjuvant }\end{array}$ & $\begin{array}{l}\text { Type of } \\
\text { adjuvant }\end{array}$ & $\begin{array}{c}\text { Compressive } \\
\text { strength at } 7 \\
\text { days - MPa }\end{array}$ & $\begin{array}{c}\text { Compressive } \\
\text { strength at } 28 \\
\text { days- MPa }\end{array}$ \\
\hline \multirow{3}{*}{$50 \%$} & $0.5 \%$ & \multirow{3}{*}{$\begin{array}{l}\text { Tempo } \\
10 \mathrm{M}\end{array}$} & 14,35 & 19,9 \\
\hline & $1 \%$ & & 17,47 & 21,45 \\
\hline & $1.5 \%$ & & 12,87 & 16,03 \\
\hline
\end{tabular}

\section{Porosity and density of hardened concrete}

The porosity test was carried out according to NF P18-459 [21]

The test protocol is as follows:

- Formulation of concrete according to the quality required in test format,

- Leave 28 days in order to carry out tests on hardened concrete at 28 days of service life,

- After 28 days, place the test piece in a vacuum apparatus at a $\mathrm{P}<25$ mbar for at least 4 hours,

- $\quad$ Reconnect the container to the vacuum pump and gradually introduce the imbibition liquid (drinking water) so that after $15 \mathrm{~min}$ the test pieces are covered with approximately $20 \mathrm{~mm}$ of water and maintain this pressure for a minimum of 44 hours.

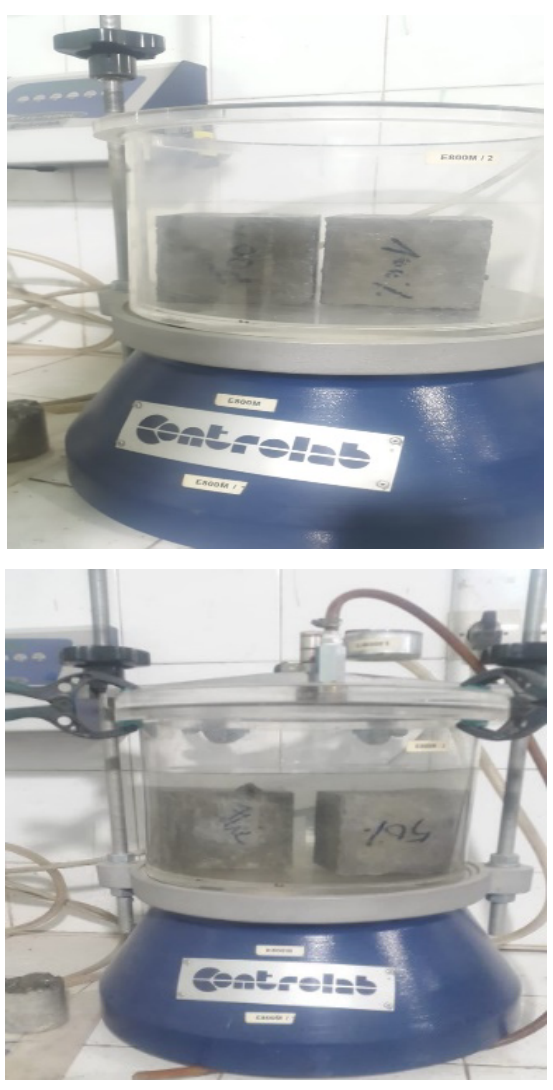

Figure 3: the test pieces placed in the vacuum apparatus for 24 hours 
The test carried out according to standard NF P 18-459 aims to determine the densities and porosities of various samples with different percentages of recycled aggregates replacing natural aggregates.

The density will thus be

$$
\rho_{d}=\frac{M_{\text {sec }}}{M_{\text {air }}-M_{\text {eau }}} \times \rho_{\text {eau }}
$$

And the porosity

$$
£=\frac{M_{\text {air }}-M_{\text {sec }}}{M_{\text {air }}-M_{\text {eau }}} \times 100
$$

with

$M_{\text {eau }}$ : The mass of the specimen inhibited in the suspension system of the hydrostatic balance.

$\mathrm{M}_{\text {air: }}$ The mass of the test tube measured immediately after removing it from the water and wiping quickly to remove surface water without removing water from the pores.

$M_{\text {sec }}$ : The mass of the oven-dried test piece.

The tests were carried out in an approved laboratory as part of the durability study of concrete made from recycled aggregates. The protocol is illustrated below:

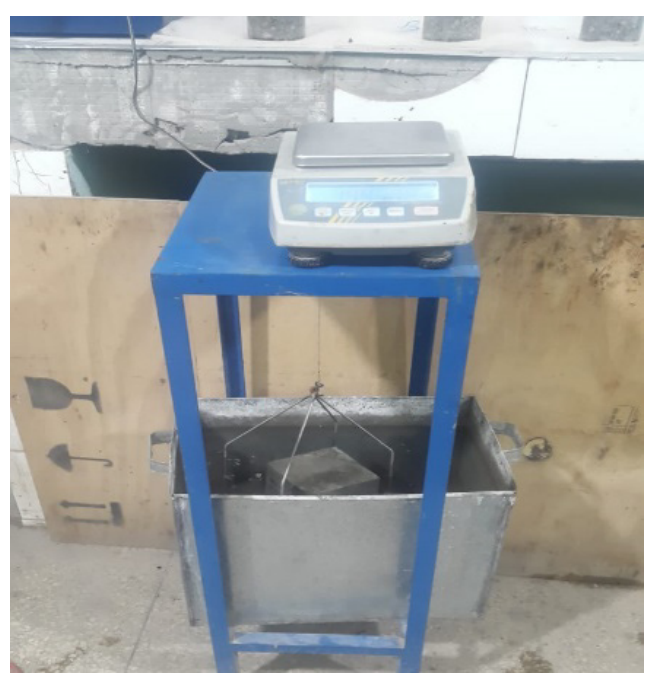

Figure 4: Procedure for calculating $M_{\text {eau }}$

The results of the tests are collated in the following tables:

Table 8: The density experimental results

\begin{tabular}{|l|c|c|c|c|c|}
\hline & $M_{\text {sec }}$ & $M_{\text {air }}$ & $M_{\text {eau }}$ & \multicolumn{2}{|c|}{$\rho_{d}$} \\
\hline \multirow{3}{*}{$100 \%$} & 2322,2 & 2464,1 & 1444,8 & 2,278 & 2,277 \\
\cline { 2 - 5 } & 2318,7 & 2459,4 & 1442,5 & 2,280 & \\
\cline { 2 - 5 } & 2310,3 & 2450,7 & 1434,8 & 2,274 & \\
\hline $75 \%$ & 2324,5 & 2465,6 & 1430,1 & 2,244 & \multirow{2}{*}{2,244} \\
\cline { 2 - 5 } & 2298,4 & 2439,9 & 1415,8 & 2,244 & \\
\cline { 2 - 5 } & 2298,3 & 2434,8 & 1410,9 & 2,244 & \\
\hline $50 \%$ & 2263 & 2423 & 1240,5 & 1,913 & \multirow{2}{*}{1,920} \\
\cline { 2 - 5 } & 2271,6 & 2429,4 & 1247,7 & 1,922 & \\
\hline
\end{tabular}

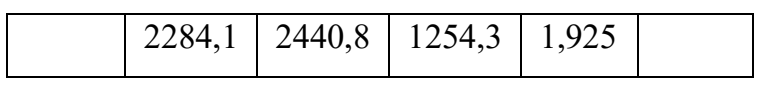

Table 9: The porosity experimental results

\begin{tabular}{|l|c|c|c|c|c|}
\hline & $M_{\text {sec }}$ & $M_{\text {air }}$ & $M_{\text {eau }}$ & \multicolumn{2}{|c|}{$E$} \\
\hline \multirow{7}{*}{$100 \%$} & 2322,2 & 2464,1 & 1444,8 & 13,921 & 13,859 \\
\cline { 2 - 5 } & 2318,7 & 2459,4 & 1442,5 & 13,836 & \\
\cline { 2 - 5 } & 2310,3 & 2450,7 & 1434,8 & 13,820 & \\
\hline $75 \%$ & 2324,5 & 2465,6 & 1430,1 & 13,626 & 13,591 \\
\cline { 2 - 5 } & 2298,4 & 2439,9 & 1415,8 & 13,817 & \\
\cline { 2 - 5 } & 2298,3 & 2434,8 & 1410,9 & 13,331 & \\
\hline $50 \%$ & 2263 & 2423 & 1240,5 & 13,530 & 13,36 \\
\cline { 2 - 5 } & 2271,6 & 2429,4 & 1247,7 & 13,353 & \\
\cline { 2 - 5 } & 2284,1 & 2440,8 & 1254,3 & 13,206 & \\
\hline
\end{tabular}

\subsection{Results interpretation}

The density increases with the increase in the rate of restitution. This is justified by the difference between the density of natural aggregates around $2000 \mathrm{~kg} / \mathrm{m}^{3}$ and the density of recycled aggregates from reinforced concrete with a density of $2500 \mathrm{~kg} / \mathrm{m}^{3}$

- Porosity, too, changes with the increase of recycled aggregates. This is justified by the characteristics of the recycled aggregates which consist of a natural aggregate coated in old cement, all coated in cement.

In order to interpret the results of our concrete in relation to its performance in terms of durability, the summary table of indicators following the Performantial Approach is used, based on various sustainability guides. (Table 10)

The buildings are subdivided into five categories according to the required lifespan:

- $\quad<30$ years

- From 30 to 50 years old: Building

- $\quad$ From 50 to 100 years: Building and civil engineering works

- $\quad$ From 100 to 120 years: Major works

- $\quad>120$ years: So-called exceptional works

Our study will be based on the first three categories due to the primary choice of the types of projects targeted by our concrete, which can be summed up in ordinary construction: Building or landscaping.

Based on durability indicators following the Performantial Approach, the recycled aggregates concrete might be used for all constructions with a lifespan of less than 30 years and all constructions with a lifespan of 30 to 50 years (Building) except those in:

- Tidal zone

- Immersion in water containing chlorides

- High exposure to sea salts or de-icing, but not in direct contact with seawater 
Table 10: Summary table of indicators following the Performantial Approach[22] ( P: porosity)

\begin{tabular}{|c|c|c|c|c|c|c|}
\hline $\begin{array}{l}50-100 \\
\text { Building and civil } \\
\text { engineering works } \\
\text { Level } 3\end{array}$ & $\begin{array}{l}30-50 \\
\text { Building } \\
\text { Level } 2\end{array}$ & Level 1 & \multicolumn{2}{|c|}{$\begin{array}{l}\text { Required life } \\
\text { Construction category }\end{array}$} & 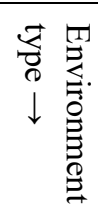 & \\
\hline $\mathrm{P}<14$ & $\mathrm{P}<16$ & $\mathrm{P}<16$ & \multicolumn{2}{|c|}{$\begin{array}{l}\text { - Dry and very dry }(\mathrm{RH}<65 \%) \\
\text { - Permanently wet (including immersion in fresh water) }\end{array}$} & 1 & \multirow{4}{*}{ 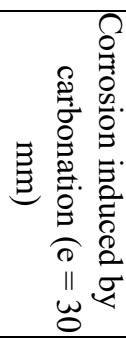 } \\
\hline $\mathrm{P}<14$ & $\mathrm{P}<16$ & $\mathrm{P}<16$ & \multicolumn{2}{|c|}{ Wet, rarely dry $(\mathrm{RH}>80 \%)$} & 2 & \\
\hline $\mathrm{P}<12$ & $\mathrm{P}<14$ & $\mathrm{P}<15$ & \multicolumn{2}{|c|}{ Moderate humidity $(65<\mathrm{RH}<80 \%)$} & 3 & \\
\hline $\mathrm{P}<12(5)$ & $\mathrm{P}<14(4)$ & $\mathrm{P}<16$ & \multicolumn{2}{|c|}{$\begin{array}{l}\text { Periods of humidity alternating with dry periods without } \\
\text { chloride (de-icing salts, spray, etc.) }\end{array}$} & 4 & \\
\hline $\mathrm{P}<14$ & $\mathrm{P}<15$ & $\mathrm{P}<16$ & $5.1:$ low $[\mathrm{Cl}-]$ & \multirow[t]{2}{*}{$\begin{array}{l}\text { Exposure to sea salts or de-icing, but not } \\
\text { in direct contact with seawater }\end{array}$} & 5 & \multirow{3}{*}{ 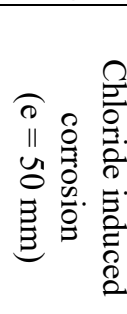 } \\
\hline$\cdot \mathrm{P}<11$ & $\mathrm{P}<11$ & $\mathrm{P}<14$ & 5.2 : high $[\mathrm{Cl}-]$ & & & \\
\hline$\cdot \mathrm{P}<13$ & $\mathrm{P}<13$ & $\mathrm{P}<15$ & \multicolumn{2}{|c|}{ Immersion in water containing chlorides } & 6 & \\
\hline$\cdot \mathrm{P}<11$ & $\mathrm{P}<11$ & $\mathrm{P}<14$ & \multicolumn{2}{|l|}{ Tidal zone } & 7 & \\
\hline
\end{tabular}

Added to this, the possible use of the concrete is constructions with a lifespan of 50 to 100 years (Building and Civil Engineering Works) under the following conditions:

- Low exposure to sea salts or de-icing, but not in direct contact with sea water

- Humid environment, rarely dry $(\mathrm{RH}>80 \%)$

- Dry and very dry environment $(\mathrm{RH}<65 \%)$

- Permanently humid environment (including immersion in fresh water)

Depending on the durability indicators, to use the concrete is other types of construction other in-depth studies should carry out and improvement in the concrete quality should be made.

\section{Conclusion}

This article is part of a series of test protocols carried out as part of the study of the performance of recycled aggregate concrete.

The study began with a mechanical comparison of ordinary concrete with recycled aggregate concrete with various replacement rates. These tests allowed us to deduce that for a basic concrete (without additions), the maximum replacement rate to meet the development conditions is around $25-30 \%$. Beyond this value, training improvements will need to be made. In this sense, the addition of various admixtures has enabled us to deduce that super-plasticizers improve the quality of our concrete for replacement rates of 30 to $50 \%$. Other changes might been used as explained in many researches studies: Change in the $\mathrm{E} / \mathrm{C}$ ration, restitution of aggregates on one class only, primary sorting of aggregates.
The next step, the subject of this article, was to study the durability of recycled aggregate concrete. This study proves us that, overall, our new formulation complies with regulations in terms of manageability indicators for basic constructions.

At this stage, in order to finalize our protocol, an overview with a technical-economical comparison must be made in order to conclude the technical and economic reliability of the proposed product.

\section{Conflict of Interest}

The authors declare no conflict of interest.

\section{References}

[1] H. Guo, C. Shi, X. Guan, J. Zhu, Y. Ding, T.C. Ling, H. Zhang, Y. Wang , "Durability of recycled aggregate concrete - A review", Cement and Concrete Composites, 89, 251-259, 2018, doi: 10.1016/j.cemconcomp.2018.03.008

[2] S.H. Liu, P.Y. Yan, "Properties and microstructure of high performance recycled aggregate concrete", Journal-chinese ceramic society, 35(4), 456460, 2007.

[3] J. de Brito, J. Ferreira, J. Pacheco, D. Soares, M. Guerreiro, "Structural, material, mechanical and durability properties and behaviour of recycled aggregates concrete", Journal of Building Engineering, 6, 1-16, 2016, doi : 10.1016/j.jobe.2016.02.003.

[4] M. Bravo, J. de Brito, J. Pontes, L. Evangelista, "Durability performance of concrete with recycled aggregates from construction and demolition waste plants", Construction and Building Materials, 77, 357-369, 2015, doi: 10.1016/j.conbuildmat.2014.12.103

[5] I. Martínez-Lage, F. Martínez-Abella, C. Vázquez-Herrero, J.L. PérezOrdóñez, "Properties of plain concrete made with mixed recycled coarse aggregate", Construction and Building Materials, 37, 171-176, 2012, doi: 10.1016/j.conbuildmat.2012.07.045

[6] R. Kurda, J. de Brito, J. D. Silvestre, "Combined influence of recycled concrete aggregates and high contents of fly ash on concrete properties", Construction and Building Materials, 157, 554-572, 2017, doi: 10.1016/j.conbuildmat.2017.09.128. 
[7] O. Nobuaki, M. Shin-Ichi, Y. Wanchai, "Influence of recycled aggregate on interfacial transition zone, strength, chloride penetration and carbonation of concrete", Journal of Materials in Civil Engineering, 15(5), 443-451, 2003, doi: 10.1061/ (ASCE) 0899-1561(2003)15:5(443).

[8] E. Vázquez, M. Barra, D. Aponte, C. Jiménez, S. Valls, "Improvement of the durability of concrete with recycled aggregates in chloride exposed environment", Construction and Building Materials, 67, 61-67, 2014, doi : 10.1016/j.conbuildmat.2013.11.028.

[9] R.M. Salem, E.G. Burdette, N.M. Jackson, "Resistance to freezing and thawing of recycled aggregates concrete", ACI Materials Journal, 100(3), 216-221, 2003, doi:

[10] J.Y. Sun, J. Geng, "Effect of partical size and content of recycled fine aggregate on frost resistance of concrete", Journal of Building Materials, 15, 382-385, 2012, doi: 10.3969/j.issn.1007-9629.2012.03.017.

[11] R.M. Salem, E.G. Burdette, "Role of c-hemical and admixtures on physical and frost resistance of recycled aggregate concrete", ACI Materials Journal, 95 (5), 558-563, 1998, doi: 10.14359/398.

[12] Q.T. Liu, G.P. Cen, L.C. Cai, H.S. Wu, "Frost-resistant performance and mechanism of recycled concrete for airport pavement", Journal Huazhong University for science \& Technology, 39(12), 128-132, 2011.

[13] D. Xuan, B. Zhan, C.S. Poon, "Durability of recycled aggregate concrete prepared with carbonated recycled concrete aggregates", Cement and Concrete Composites, 84, 214-221, 2017, doi: 10.1016/j.cemconcomp.2017.09.015.

[14] S.C. Kou, C.S. Poon, "Enhancing the durability properties of concrete prepared with coarse recycled aggregate", Construction Building Materials, 35, 69-76, 2012, doi: 10.1016/j.conbuildmat.2012.02.032.

[15] J.P. Hwang, H.B. Shim, S. Lim, K.Y. Ann, "Enhancing the durability properties of concrete containing recycled aggregate by the use of pozzolanic materials", Ksce Journal of Civil Engineering, 17, 155-163, 2013, doi: 10.1007/s12205-013-1245-5.

[16] S.C. Kou, C.S. Poon, "Properties of concrete prepared with PVA-impregnated recycled concrete aggregates", Cement and Concrete Composites, 32, 649654, 2010, doi: 10.1016/j.cemconcomp.2010.05.003.

[17] V.W.Y. Tam, C.M. Tam, "Assessment of durability of recycled aggregate concrete produced by two-stage mixing approach", Journal of materials science, 42, 3592-3602, 2007, doi: 10.1007/s10853-006-0379-y.

[18] X.H. Li, L.G. David, "Mitigating alkali-silica reaction in concrete containing recycled concrete aggregate", Journal of the transportation research board, 1979, 30-35, 2006, doi: 10.1177/0361198106197900105.

[19] P. Saravanakumar, G. Dhinakaran, "Durability aspects of HVFA-based recycled aggregate concrete", Magazine of Concrete Research, 66(4), 186195, 2014, doi: 10.1680/macr.13.00200.

[20] Y.G. Zhu, S.C. Kou, C.S. Poon, J.G. Dai, Q.Y. Li, "Influence of silane-based water repellent on the durability properties of recycled aggregate concrete", Cement and Concrete Composites, 35(1), 32-38, 2013, doi: 10.1016/j.cemconcomp.2012.08.008.

[21] AFNOR, NF P18-459: Béton - Essai pour béton durci - Essai de porosité et de masse volumique, 2010.

[22] Association Française de Génie Civil, Conception des bétons pour une durée de vie donnée des ouvrages : maitrise de la durabilité vis-à-vis de la corrosion des armatures et de l'alcali-réaction Etat de l'art et Guide pour la mise en œuvre d'une approche performantielle et prédictive sur la base d'indicateurs de durabilité, 2004. 
